Review

\title{
A Perspective on Low-Temperature Water Electrolysis - Challenges in Alkaline and Acidic Technology
}

\author{
Maximilian Schalenbach ${ }^{1, *}$, Aleksandar R. Zeradjanin ${ }^{1,2}$, Olga Kasian $^{1}$, Serhiy Cherevko ${ }^{1,2}$, \\ Karl J.J. Mayrhofer ${ }^{1,2,3, *}$ \\ ${ }^{1}$ Department of Interface Chemistry and Surface Engineering, Max-Planck-Institut für Eisenforschung \\ GmbH, Max-Planck-Strasse 1, 40237 Düsseldorf, Germany \\ ${ }^{2}$ Helmholtz-Institute Erlangen-Nürnberg for Renewable Energy (IEK-11), Forschungszentrum Jülich, \\ Egerlandstr. 3, 91058 Erlangen, Germany \\ ${ }^{3}$ Department of Chemical and Biological Engineering, Friedrich-Alexander-Universität Erlangen- \\ Nürnberg, Egerlandstr. 3, 91058 Erlangen, Germany \\ *E-mail: m.schalenbach@mpie.de, k.mayrhofer@fz-juelich.de
}

doi: $10.20964 / 2018.02 .26$

Received: 31 October 2017 / Accepted: 1 December 2017 / Published: 28 December 2017

\begin{abstract}
Water electrolysis is considered as an important technology for an increased renewable energy penetration. This perspective on low-temperature water electrolysis joins the dots between the interdisciplinary fields of fundamental science describing physicochemical processes, engineering for the targeted design of cell components and the development of operation strategies. Within this aim, the mechanisms of ion conduction, gas diffusion, corrosion and electrocatalysis are reviewed and their influence on the optimum design of separators, electrocatalysts, electrodes and other cell components are discussed. Electrocatalysts for the water splitting reactions and metals for system components are critically accessed towards their stability and functionality. On the basis of the broad scientific analysis provided, challenges for the design of water electrolyzers are elucidated with special regard to the alkaline or acidic media of the electrolyte.
\end{abstract}

Keywords: Hydrogen Evolution Reaction (HER), Oxygen Evolution Reaction (OER), Hydrogen Production, Electrocatalysts, Electrolytes

\section{$\underline{\text { FULL TEXT }}$}

(C) 2018 The Authors. Published by ESG (www.electrochemsci.org). This article is an open access article distributed under the terms and conditions of the Creative Commons Attribution license (http://creativecommons.org/licenses/by/4.0/). 